\title{
Clinico-Physiological Response to Detomidine-Propofol Anaesthesia in Atropinized Goats
}

\author{
M.S. Maravi, Rukmani Dewangan ", S.K. Tiwari, R. Sharda and M.O. Kalim \\ Department of Veterinary Surgery and Radiology, College of Veterinary Science, \\ Anjora, Durg (C.G.), India \\ *Corresponding author
}

\section{A B S T R A C T}

The study was conducted on six healthy non-descript goats of either sex weighing 20-25 $\mathrm{kg}$ by giving atropine sulphate $(0.04 \mathrm{mg} / \mathrm{kg} \mathrm{I} / \mathrm{M})$ followed by detomidine $(15 \mu \mathrm{g} / \mathrm{kg} \mathrm{I} / \mathrm{M})$

\section{Keywords}

Anaesthesia, Atropine sulphate, Clinicophysiological response, Detomidine, Goats, Propofol

Article Info

Accepted:

26 January 2018

Available Online:

10 February 2018 and $10 \mathrm{~min}$. later followed by induction of anaesthesia with propofol $(5 \mathrm{mg} / \mathrm{kg} \mathrm{I} / \mathrm{V})$. There was decrease in spontaneous activity with marked sedation as well as lowering of head after detomidine administration in all the animals. After administration of propofol, there was rapid and smooth induction of anaesthesia $(0.46 \pm 0.51 \mathrm{~min})$. Transient apnoea was observed immediately after induction with propofol which lasted for 40-50 seconds. This was followed by loss of swallowing reflex, corneal, palpebral and conjunctival reflexes were abolished within $3 \mathrm{~min}$ and remained so throughout the anaesthetic period. The anal pinch and pedal reflexes were also fully abolished. Muscle relaxation was excellent. Complete analgesia at fetlock, base of tail, abdomen, ribs and base of horn was observed. The duration of anaesthesia was $52.50 \pm 8.44 \mathrm{~min}$ and complete recovery which was smooth with no excitement occured within $91.66 \pm 14.24 \mathrm{~min}$. There was non-significant decrease in the rectal temperature. Heart and respiration rate significantly decreased upto $60 \mathrm{~min}$. after detomidine-propofol administration. It can be concluded that detomidinepropofol anaesthesia may be safely used for inducing longer duration of anaesthesia in goats.

\section{Introduction}

General anaesthesia produces unconsciousness, analgesia and muscle relaxation but might also suppress autonomic reflex activity and consequently leads to inadequate function of vital physiological systems such as the cardiovascular and respiratory system (Antognini and Carstens, 2002). The choice of anaesthetic drugs and timing of surgical intervention is important in both normal and diseased animal. However, rapid and smooth induction of anaesthesia and lesser duration of recumbency are desirable. No single anaesthetic is known to posses all the components of the ideal general anaesthetic agent without depressing some vital function. Therefore, multiple drug approach is exploited to diminish sensory, motor, sympathetic and parasympathetics reflex activities and to attenuate individual components of the anaesthetic state. Propofol is a non-barbiturate, intravenous anaesthetic agent commonly used in veterinary and human 
anaesthetic practice (Bodh et al., 2013), which rapidly induces smooth anaesthesia, and permit fast and uneventful recovery. The rapid induction and short duration of action, with rapid recoveries make propofol potentially useful in calves (Branson and Gross, 1994). However, when used alone, propofol is unsatisfactory; consequently, it has been combined with various sedatives and analgesic drugs to produce adequate surgical conditions (Cullen and Reynoldson, 1993). It is recommended to premedicate goats so that they are calm before administering these induction agents (Galatos, 2011). Atropine sulphate is used as preanaesthetic to prevent salivary, bronchial, tracheal and gastric secretions and to inhibit the bradycardiac effects of vagal stimulation. Detomidine $\mathrm{HCl}$ is a new synthetic alpha-2 adrenorecptor agonist and is imidazole derivative with sedative and analgesic properties (Anonymous, 1996) which is primarily used as sedative in horses. Reports regarding use of propofol anaesthesia in combination with detomidine as premedicant in goats are limited; therefore, the present paper deals with the clinico-physiological response to detomidine-propofol anaesthesia in atropinized goats.

\section{Materials and Methods}

The present study was conducted in six healthy non-descript goats of either sex weighing between $20-25 \mathrm{~kg}$ using atropine sulphate @ $0.04 \mathrm{mg} / \mathrm{kg} \mathrm{I} / \mathrm{M}$ followed by detomidine $(15 \mu \mathrm{g} / \mathrm{kg} \mathrm{I} / \mathrm{M})$ and $10 \mathrm{~min}$. later followed by induction of anaesthesia with propofol $(5 \mathrm{mg} / \mathrm{kg} \mathrm{I} / \mathrm{V})$. The following clinical parameters were studied are onset of sedation / anaesthesia, spontaneous activity, lowering of head, salivation, onset of sternal or lateral recumbency and duration of anaesthesia. Depth of anaesthesia was judged by monitoring the loss of swallowing reflex, corneal, conjunctival, palpebral reflexes, relaxation of anal sphincter anal pinch, pedal reflexes and extent of muscle relaxation. Recovery from anaesthesia was monitored raising of head, trying to stand with ataxia and complete recovery i.e. standing without ataxia. The physiological parameters includes rectal temperature, heart rate and respiratory rate which were recorded before and 10 minutes after premedication and 10, 20, 40, 60, 90, 120 and 180 minutes after propofol anaesthesia. The mean and standard error of recorded values were calculated. One way analysis of variance (ANONA) and Duncan's multiple range test were used to compare the means at different intervals with base values as per the standard procedure outlined by Snedecor and Cochran (1994).

\section{Results and Discussion}

There was decrease in spontaneous activity in all the animals after detomidine administration with marked sedation as well as lowering of head. The sedative action of $\alpha_{2}$-adrenergic agonists is due to inhibition of firing of locus coeruleus (LC) neurons in the pons of the lower brain stem and its ascending activating projection to the forebrain after systemic injection. Urination and defaecation was observed in two animals after detomidine administration. Moderate cutaneous analgesia was observed in animals on pin-prick at abdomen, tail and base of horn. Pedal and palpebral reflexes were present in all animals. All the animals fell down to lateral recumbency after administration of detomidine. Singh et al., (1991) reported salivation after administration of detomidine in goats. Head drooping with detomidine had also been reported in horses (Skarda and Muir., 1996) and in sheep (Malhi et al., 2015). After administration of propofol, there was rapid and smooth induction of anaesthesia. The onset of anaesthesia was $0.46 \pm 0.51$ minutes. Rapid onset of action is caused by rapid uptake of propofol into the CNS and 
induction of depression occurs by enhancing the effect of the inhibitory neurotransmitter GABA and decreasing the metabolic activity of the brains (Concas et al., 1991). Adetunji et al., (2002) also found that propofol provided rapid induction of anaesthesia after its administration due to its high lipid solubility resulting in rapid blood / brain equilibrium. The duration of anaesthesia was $52.50 \pm 8.44$ minutes. There was loss of swallowing reflex, corneal, palpebral conjunctival and panniculus reflexes and abolished within 3 min which remained throughout the period of anaesthesia. The anal pinch and pedal reflexes were fully abolished. The muscle relaxation was excellent. Complete analgesia at fetlock, base of tail, abdomen, ribs and base of horn was observed. Sluggish to absent corneal reflex was observed after induction of propofol anaesthesia (Singh et al., 2014 and Potliya et al., 2015 a, b) in buffalo calves. Increase in the duration of anaesthesia was correlated with the additive effect of preanaesthetics with propofol in depressing the activity of the cerebral cortex.

Kilic (2008) concluded that the combination of detomidine, midazolam and ketamine resulted in anaesthesia lasting about $45 \mathrm{~min}$ in calves. Various pre-anaesthetic combination have been used with propofol to prolong the duration of anaesthesia alongwith shorter recovery time, thereby improving quality of anaesthesia (Potliya et al., 2015 b). In the present study, detomidine was combined with propofol to prolong the duration of anaesthesia and produce profound analgesia with excellent muscle relaxation. After detomidine-propofol administration, there was excellent muscle relaxation which might be due to prior administration of detomidine which activates alpha-2adrenoceptors present in the spinal cord (Branson et al., 1993). Recovery was manifested by raising of head at $52.50 \pm 8.44$ minutes and was smooth, free from excitement, without any struggling. All the animals returned to sternal recumbency at 60 \pm 4.50 minutes. All the animals tried to stand with ataxia at $75.5 \pm 3.50$ and complete recovery occurred $91.66 \pm 14.24$ minutes after propofol administration. Potliya et al., (2015 a, b) observed that complete recovery took $198.0 \pm 9.75 \mathrm{~min}$. and $132.0 \pm 8.63 \mathrm{~min}$. to occur in buffalo calves after administration of atrophine-xylazine-propofol and glycopyrrolate-xylazine-propofol

combinations, respectively. The effects on physiological parameters after detomidinepropofol anaesthesia in atropinized goats at various time intervals are shown in Table 1. A non-significant decrease in the rectal temperature was observed after administration of propofol in combination with detomidine which persisted upto $90 \mathrm{~min}$. (from $103.5 \pm 0.20$ to $\left.102 . \pm 0.17^{\circ} \mathrm{F}\right)$. The decrease in rectal temperature was also probably the result of a reduced basal metabolic rate (BMR) and muscle activity, and depression of thermoregulatory centre (Kilic, 2008).

Rectal temperature slightly decreased after administration of detomidine in Pateri goat and this decrease was non-significant as compared to the control values (Tunio et al., 2016). Reduced rectal temperature had been reported during propofol anaesthesia in goats (Carroll et al., 1998; Amarpal et al., 2002). The reduction in rectal temperature is considered secondary to CNS depression and reduction in the muscular activity (Kammar et al., 2014). Highly significant $(\mathrm{p}<0.01)$ decrease in heart rate was observed from base value upto $120 \mathrm{~min}$ (from $77.66 \pm 0.76$ to $66.16 \pm 0.40$ beats/min.) after the administration of atropine-detomidinepropofol with a peak decrease at $60 \mathrm{~min}$. $(50.16 \pm 1.35$ beats/min). However, the values increased and returned to preadministration level by $180 \mathrm{~min}$. The decrease in the HR might be attributed to vasoconstriction due to alpha-2 agonist administration leading to reflex bradycardia (Lemke, 2004). 
Table.1 Effects on physiological parameters after detomidine-propofol anaesthesia in atropinized goats at various time intervals (Mean \pm S.E.)

\begin{tabular}{|c|c|c|c|c|c|c|c|c|c|}
\hline \multirow[t]{2}{*}{ Groups } & \multicolumn{9}{|c|}{ Time Intervals(min) } \\
\hline & $\mathbf{0}$ & $\begin{array}{l}10 \text { min after } \\
\text { pre- } \\
\text { medication }\end{array}$ & $\begin{array}{l}10 \mathrm{~min} \\
\text { after } \\
\text { G.A. }\end{array}$ & 20 & 30 & 60 & 90 & 120 & 180 \\
\hline $\begin{array}{c}\text { Rectal } \\
\text { Temperature } \\
\left({ }^{\circ} \mathbf{F}\right) \\
\end{array}$ & $\begin{array}{l}103.5 \\
\pm 0.20\end{array}$ & $\begin{array}{l}103.0 \\
\pm 0.20\end{array}$ & $\begin{array}{l}102.8 \\
\pm 0.20\end{array}$ & $\begin{array}{r}102.6 \\
\pm 0.19\end{array}$ & $\begin{array}{l}102.4 \\
\pm .0 .17\end{array}$ & $\begin{array}{r}102.2 \\
\pm 0.18\end{array}$ & $\begin{array}{l}102.00 \\
\pm 0.17\end{array}$ & $\begin{array}{l}103.0 \\
\pm 0.19\end{array}$ & $\begin{array}{l}103.3 \\
\pm 0.19\end{array}$ \\
\hline $\begin{array}{c}\text { Heart Rate } \\
\text { (Beats/ Minute) }\end{array}$ & $\begin{array}{r}77.66 \\
\pm 0.76\end{array}$ & $\begin{array}{l}72.00 \\
\pm 1.26\end{array}$ & $\begin{array}{l}61.66 * * \\
\pm 1.66\end{array}$ & $\begin{array}{l}58.83 * * \\
\pm 2.30\end{array}$ & $\begin{array}{l}53.50 * \\
* \pm 2.12\end{array}$ & $\begin{array}{l}50.16 * * \\
\pm 1.35\end{array}$ & $\begin{array}{l}56.16 * * \\
\pm 0.40\end{array}$ & $\begin{array}{l}66.33 * \\
\pm 1.89\end{array}$ & $\begin{array}{r}74.83 \\
\pm 0.90\end{array}$ \\
\hline $\begin{array}{l}\text { Respiration Rate } \\
\text { (per minute) }\end{array}$ & $\begin{array}{l}22.00 \\
\pm 0.51\end{array}$ & $\begin{array}{l}18.00 \\
\pm 0.25\end{array}$ & $\begin{array}{l}15.00 * \\
\pm 0.81\end{array}$ & $\begin{array}{l}12.16^{* * *} \\
\pm 0.30\end{array}$ & $\begin{array}{l}10.50 * \\
* \pm 0.34\end{array}$ & $\begin{array}{l}9.66^{* * *} \\
\pm 0.49\end{array}$ & $\begin{array}{l}16.00 * \\
\pm 1.39\end{array}$ & $\begin{array}{l}17.05^{*} \\
\pm 1.28\end{array}$ & $\begin{array}{l}21.36 \\
\pm 0.60\end{array}$ \\
\hline
\end{tabular}

$* \mathrm{P}<0.05=$ Significant at $5 \%$ level when compared to base value

$* * \mathrm{P}<0.01=$ Significant at $1 \%$ level when compared to base value

Inhibition of sympathetic tone from the central nervous system, inhibition of norepinephrine release from sympathetic nerve terminals, vagal activity in response to detomidine induced vasoconstriction and direct increase in the release of acetylcholine from the parasympathetic nerves in the heart have been described as possible mechanisms by which detomidine induces bradycardia (MacDonald and Virtanen, 1992). Tunio et al., (2016) in goats reported decreased HR after detomidine administration. The decrease in heart rate might also be due to propofol induced vasodilatation leading to a fall in systemic vascular resistance as well as dose related depression of myocardial contractibility (Duke, 1995).This might be due to direct action of $\alpha_{2}$-agonist on the post synaptic receptors of the vascular smooth muscles leading to vasoconstriction and an initial transient hypertension followed by pronounced hypotension. Xylazine-propofol and medetomidine-propofol combinations produce bradycardia in goats which was pronounced after premedication with medetomidine (Amarpal et al., 2002). The animals showed a significant $(\mathrm{p}<0.05)$ decrease in the respiration rate up to $120 \mathrm{~min}$. (from $22.00 \pm 0.51$ to $17.05 \pm 1.28$ per min.) which became highly significant $(\mathrm{p}<0.01)$ at $60 \mathrm{~min}$. (from $22.00 \pm 0.51$ to $9.66 \pm 0.49$ per min.) with peak decrease after anaesthesia. Apnoea is common following bolus administration of propofol or thiopentone and increasing the dose or speed of injection will increase the incidence and duration of apnoea (Bodh et al., 2013). In the present study, transient apnoea was observed immediately after propofol administration which lasted for 40 to 50 seconds in all the animals. Bufalari $e t$ al., (1998) also opined that respiratory depression might cause transient apnoea. A transient apnoea of about 2 minutes has been reported immediately after administration of thiopentone in buffalo calves premedicated with atropine and diazepam (Singh et al., 2006). Similar findings were reported with propofol by Carroll et al., (1998) in goat. Decrease in respiration rate, might be due direct depressant action of $\alpha_{2}$-agonist (detomidine) on central nervous system in general and respiratory centre in particular (Kim et al., 1999). In the present study, after propofol injection there was significant $(p<0.05)$ decrease in the respiration rate, thereafter it returned to near normal values by $120 \mathrm{~min}$ of the study period. However, in the present study, the transient changes in 
physiological parameters were compensated within $180 \mathrm{~min}$. and remained within physiological limits. Therefore, it can be concluded that the detomidine-propofol anaesthesia may be safely used for inducing longer duration of anaesthesia in atropinized goats as it produced profound analgesia with quicker onset of induction of anaesthesia with excellent muscle relaxation along with smooth and uneventful recovery.

\section{References}

Adetunji, A., Ajadi, R. A., Adewoye, C. O. and Oyemakinde, B. O. 2002. Total intravenous anaesthesia with propofol: Repeat bolus versus continuous propofol infusion technique in xylazine premedicated dogs. Israel J. Vet. Med. 57: 139-144.

Amarpal, Kinjavdekar, P., Aithal, H. P., Pathak, R., Pratap, K. and Singh, V. 2002. Effect of xylazine and medetomidine premedication of propofol anaesthesia in goats. Indian $J$. Anim. Sci. 72: 565-566.

Anonymous. 1996. Dermosedan (Detomidine $\mathrm{HCl})$. Sedative and analgesic for use in horses only. Orion-Farmos, Espoo, Finland.

Antognini, J. F. and Carstens, E. 2002. In vivo characterization of clinical anaesthesia and its components. Br. J. Anaesth., 89(1): 156-66.

Bodh, D., Singh, K., Mohindroo, J., Mahajan, S.K., Anand, A. and Saini, N. S. 2013. Propofol and thiopentone sodiam as induction agent in water buffaloa; a comparative study Journal of Applied Animal Research, 41(3): 370 -373.

Branson, K. R. and Gross, M. E. (1994). Propofol in veterinary medicine. J. Am. Vet. Med. Ass. 204:1888-1890.

Branson, K. R., Ko, J. C. H., Tranquilli, W. J., Benson, J. and Thurmon, J. C. 1993. Duration of analgesia induced by epidurally administered morphine and medetomidine in the dog. J. Vet. Pharmacol. Therap., 16:369-372

Bufalari, A., S. M., Millar, C., Giannoni and Short, C. E. 1998. The use of propofol as an induction agent for halothane and isoflurane anaesthesia in dogs. J.Am.Anim.Hosp.Assoc., 34:84-91.

Carroll, G. L., Hooper, R. N., Slater, M. R., Hartsfield, S. M. and Matthews, N. S. 1998. Detomidine-ButorphanolPropofol for carotid artery translocation and castration or ovariectomy in goats. Veterinary Surgery, 27: 75-82.

Concas, A., Santoro, G. and Serra, M. 1991. Neurochemical action of the general anaesthetic propofol on the chloride ion channel coupled with GABA receptors. Brain Research, 542: 225-232.

Cullen, L. K. and Reynoldson, J.A. 1993. Xylazine or medetomidine premedication before propofol anaesthesia. Vet.Rec.132:378-382.

Duke, T. 1995. A new intravenous anaesthetic agent propofol. Can. Vet. J., 36 (1):181182.

Flaherty D., Reid, J., Welsh, E., Monteiro, A.M., Lerche, P. and Nolan, A. 1997. A pharmacodynamic study of propofol or propofol and ketamine infusions in ponies undergoing surgery. Res. Vet. Sci., 62: 179-184.

Galatos, A. D. 2011. Anaesthesia and analgesia in sheep and goats. Veterinary Clinics of North America:Food Animals 27: 49-59.

Kammar,M. H. EL., Gad, S. B. and Korittum, A. S. 2014. Evaluation of the sedative, analgesic, physiological and haematological effects of intravenous detomidine, detomidine-butorphanol, romifidine and romifidine-butorphanol in Baladi goats. Global Veterinaria 12(1):36-44.

Kilic, Nuh. 2008. Cardiopulmonary, biochemical and haematological 
changes after detomidine-midazolamketamine anaesthesia in calves. Bull Vet Inst Pulawy 52: 453-456.

Kim. J., Jang. I. H., Kim, J. W. and Jang, I. H. 1999. The effects of xylazine premedication on propofol anaesthesia in the dog. Korean J. Vet. Clin. Med., 16 (1): 86-94.

Lemke, K. A. 2004. Perioperative use of selective alpha-2 agonists and antagonists in small animals. Can. Vet. $J ., 45: 475-480$.

MacDonald, E. and Virtanen, R. 1992. Review of the pharmacology of medetomidine and detomidine: Two chemically similar $\alpha_{2}$-adrenoceptor agonists used as veterinary sedatives, In: Short, C.E. and Poznak, A.V. (Eds.) Animal Pain, Churchill Livingstone, New York, pp 181-191.

Malhi, M., Kachiwal, A.B., Soomro, S.A., Gandahi, J.A., and Abro, S.H. 2015. Comparison of effects of xylazine, detomidine and medetomidine on heart rate, respiratory rate and blood glucose level in sheep. Vet. Sci., 31 (1): 93-101.

Potliya, S., Kumar, A., Singh, S. and Kumar, S. 2015 a. Evaluation of efficacy and safety of atropine-xylazine-propofol anaesthesia in buffalo calves. Paper presented in XXXIX Annual Congress of ISVS held at Sher-e-Kashmir University of Agricultural Science and Technology, Kashmir Srinagar from 1-3 September 2015.

Potliya, S., Kumar, S. Singh, S. and Kumar,
S. 2015 b. Evaluation of efficacy and safety of glycopyrrolate - xylazine propofol anesthesia in buffalo calves. Vet World, 8(3):251-256.

Singh, A. P., Peshin, P. K., Singh, J., Sharifi, D. and Patil, D. B. 1991. Evaluation of detomidine as a sedative in goats. Acta Vet Hung, 39(3-4):109-114.

Singh, K., Kumar, A., Kumar, S., Potliya, S. and Singh, S. 2014. Evaluation of triflupromazine-propofol as a anaesthetic combination in buffalo calves. Haryana Vet. 53 (2):78-83.

Singh, S., Kumar, A., Singh, J., Singh, S. and Peshin, P. K. 2006. Haemodynamic effects of atropine-dizepam-thiopentone anaesthesia in buffalo calves. Indian J. Vet. Res. 15:22-30.

Skarda, R. T. and Muir, W. W. 1996. Comparison of antinociceptive, cardiovascular, and respiratory effects, head ptosis, and position of pelvic limbs in mares after caudal epidural administration of xylazine and detomidine hydrochloride solution. American J Vet Res. 57 (9): 1338-1345.

Snedecor, G. W. and Cochran, W. G. 1994. Statistical Methods, $8^{\text {th }}$ Edition, Oxfords and IBH Publishing Co., New York, p.59.

Tunio, A., Bughio, S., Sahito J. K., Shah, M.G., Ebrahimi, M. and Tunio, S. P. 2016. Observation of physiological changes after detomidine administration in Pateri Goat. Mac Vet Rev., 39(1):i-v

\section{How to cite this article:}

Maravi, M.S., Rukmani Dewangan, S.K. Tiwari, R. Sharda and Kalim, M.O. 2018. ClinicoPhysiological Response to Detomidine-Propofol Anaesthesia in Atropinized Goats. Int.J.Curr.Microbiol.App.Sci. 7(02): 2978-2983. doi: https://doi.org/10.20546/ijcmas.2018.702.362 